\title{
Abordagem etnográfica na pesquisa e intervenção em saúde mental
}

\author{
Ethnographic approaches to research \\ and intervention in mental health
}

Mônica de Oliveira Nunes ${ }^{1}$

Maurice de Torrenté ${ }^{1}$

${ }^{1}$ Departamento de Saúde Coletiva, Instituto de Saúde Coletiva, Universidade Federal da Bahia. R. Basílio da Gama s/n, Campus Universitário Canela. 40.110-040 Salvador BA. nunesm@ufba.br

\begin{abstract}
The specifics of ethnographic approaches to mental health research are examined, highlighting the motives why the type of knowledge produced by ethnography is relevant to the context of Psychiatric Reform and the biomedicalization of existence. The discussion is focused on interpretation-based ethnography in the field of mental health, stressing the theoretical and methodological foundations of a comprehensive form of apprehending the scope of mental health as an object akin to a clinic of the individual. The centrality of social and cultural aspects in the ethnographic approach and the inflexions mediated by the type of ethnographic methodological undertaking is stressed. Lastly, the ethnography of madness is seen as a fitting example that substantiates some of these characteristics. The contention is that accessing psychotic persons (and others who may speak about these experiences) from varied areas of their daily life, situated in their various social inscriptions, while confronting these interpretations with other interpretative dimensions of their social reality and within the logic linked to local psychologies, is a pertinent procedure, from whence certain aspects of an understanding of madness (or causes of its incomprehension) can emerge.
\end{abstract}

Key words Ethnography, Mental health, Psychosis, Methodology, Interpretative anthropology
Resumo Detivemo-nos sobre as particularidades das abordagens etnográficas na pesquisa em saúde mental, destacando razões pelas quais o tipo de conhecimento que a etnografia produz é relevante no contexto da Reforma Psiquiátrica e da biomedicalização da existência. Centramos nossa discussão na etnografia de base interpretativa no campo da saúde mental, enfatizando as bases teórico-metodológicas de um tipo compreensivo de apreensão do objeto que se aproxima de uma clínica do sujeito. Apontamos a centralidade do social/cultural na apreensão etnográfica e as inflexões desta mediadas pelo próprio tipo de empreendimento metodológico etnográfico. Finalmente, tomamos a etnografia da loucura como objeto exemplar para evidenciar algumas dessas particularidades. Argumentamos que acessar pessoas psicóticas (ou outras que venham a falar dessas experiências) de lugares variados no seu cotidiano e situadas a partir de suas diversas inscrições sociais e, ao mesmo tempo, confrontar essas interpretações com outras dimensões interpretativas da sua realidade social e dentro das lógicas afeitas às suas psicologias locais é um procedimento relevante de onde certos aspectos do entendimento sobre a loucura (ou sobre as razões da sua incompreensão) podem emergir.

Palavras-chave Etnografia, Saúde mental, Psicose, Metodologia, Antropologia interpretativa 


\section{Introdução}

No contexto de reorganização do sistema de saúde mental local, em 1990, Corin et al. ${ }^{1}$ lançaram uma obra intitulada Comprendre pour soigner autrement, cuja tradução seria Compreender/ Entender para cuidar de outro modo. Apresentavam uma etnografia, pautada no sistema de signos, significados e práticas, teoria e metodologia desenvolvidas pelos autores, realizada na região de Abitibi, na província do Quebec. Comparavam três espaços sociais distintos - florestal, agrícola e minerador - revelando uma malha semântica de temas em saúde mental delineando as bases socioculturais e econômicas das construções específicas do sofrimento psíquico em cada um deles.

O sentido profundo do título do livro atravessava-o, e a nós leitores, na perspectiva de uma referência ao agir transformador. Para os autores, não seria possível planejar intervenções em saúde mental para aqueles lugares sem conhecer as suas dinâmicas socioculturais instituintes dos modos de subjetividade individual e coletiva e, consequentemente, das formas de adoecimento. Planejar serviços, ou ações mais ampliadas de prevenção do sofrimento psíquico, ou de promoção da saúde mental, de determinados grupos sociais pressupunha o "conhecimento denso" das suas realidades sob pena de produzir espaços de intervenção que serviriam como "obstáculos às mudanças que se buscam introduzir".

Esse foco na produção de conhecimento necessário sobre as realidades, os fenômenos, as pessoas, as experiências, entre outros aspectos do campo da saúde mental sobre o qual queremos atuar talvez não tenha merecido a devida discussão nos nossos textos científicos. Tomando a Reforma Psiquiátrica como uma importante obra sociopolítica em curso e produtora de um horizonte ético que move muitas das práticas no nosso país, que tipo de conhecimento precisamos produzir para informá-la?

No campo da saúde coletiva, fala-se correntemente da realização de análises da situação de saúde das populações para produzir intervenções que atinjam os coletivos. Nesse campo, temse privilegiado o saber epidemiológico para desenvolver essas investigações, mais especificamente a epidemiologia social. Na saúde mental, é incongruente pensar na proeminência de métodos quantitativos para abordar as suas temáticas tendo em vista a natureza subjetiva do seu objeto, a relevância do social e do cultural na sua construção e sua forte historicidade ${ }^{2}$. Sua amplitude e complexidade requerem, sem dúvida, a colaboração de uma diversidade de teorias e de métodos. Não é à toa que, no Brasil, a discussão em torno de uma abordagem etnoepidemiológica ${ }^{3}$ encontrou, na saúde mental, solo fértil de elaboração conceitual e, eu diria, de inspiração. No entanto, sua aplicação prática ficou limitada a grupos específicos de pesquisadores, sendo a epidemiologia psiquiátrica contemporânea predominantemente objetivista, ancorada em referências diagnósticas biomédicas supostamente universalistas e pouco adequadas às culturas locais.

No rol de estudos mais afeitos às metodologias qualitativas, temos uma multiplicação de pesquisas que têm se utilizado da cartografia deleuzi$\mathrm{ana}^{4}$, da historiografia foucaultiana ${ }^{5}$, da avaliação qualitativa de base hermenêutica ${ }^{6,7}$, além de estudos etnográficos. Destes últimos encontramos uma publicação ainda pequena em periódicos nacionais ${ }^{8,9} \mathrm{e}$ com uma concentração no tema do uso de substâncias psicoativas ${ }^{10,11}$, porém com maior quantidade e variedade de temáticas nas publicações em livros ${ }^{12,13}$, teses e dissertações.

Neste artigo, nos deteremos sobre as particularidades das abordagens etnográficas na pesquisa em saúde mental, destacando razões pelas quais o tipo de conhecimento que a etnografia produz é relevante no contexto da Reforma Psiquiátrica e da biomedicalização da existência. Centraremos a discussão na etnografia de base interpretativa no campo da saúde mental, enfatizando as bases teórico-metodológicas de um tipo compreensivo de apreensão do objeto da saúde mental que se aproxima de uma clínica do sujeito. Apontaremos a centralidade do social/cultural na apreensão etnográfica e as inflexões desta mediadas pelo próprio tipo de empreendimento metodológico etnográfico. Finalmente, tomaremos a etnografia da loucura como objeto exemplar para evidenciar algumas dessas particularidades.

\section{A relevância do social no método etnográfico}

Ter por objeto o discurso social e as estruturas de significação socialmente estabelecidas ${ }^{14}, o$ trabalho da cultura ${ }^{15}$, ou o fato social ${ }^{16}$ - entre vários outros conceitos forjados no campo das ciências sociais, apesar de suas diferenças teóricas relevantes, indica o reconhecimento de uma particularidade atribuída ao social, e ao modo de apreendê-lo/produzi-lo, mais afeita às ciências sociais e marca de sua identidade. Esta marca identitária tem balizado e legitimado teorias e métodos das diversas ciências sociais como in- 
dispensáveis na análise do que é da ordem do social, cultural, histórico e político. Essa relevância não é espúria posto que marca uma posição no modo de enxergar a ordem das coisas, ou no lugar de relevância atribuído ao processo sociocultural e histórico na produção dos fenômenos, ou ainda no estatuto do social diante do psicológico ou do biológico na busca de entendimento de um fenômeno em questão, quando tomado do ponto de vista do cientista social.

Nos desafios transdisciplinares contemporâneos, ainda que os objetos mantenham suas distinções analíticas no interior de cada tradição intelectual, traçam-se metodologias mais integradoras. Isto exige, contudo, um exame mais cuidadoso de conceitos de cada campo teórico e dos modos de produção do conhecimento próprios a cada um.

Durkheim ${ }^{16}$ teorizou sobre o fato social propondo que este não é igual à soma das partes, tendo o social um "a mais" que garante a sua especificidade. Desse modo, o coletivo não é alcançado pela soma de representações, vontades, desejos, nem mesmo ações individuais. Todo coletivo tem uma dinâmica, fruto das relações sociais e são estas que produzem um objeto de outra natureza. É a esse tipo de argumento que Corin e Lauzon ${ }^{17}$ se referem quando criticam a redução individualizante de categorias sociais, realizada por certos estudos epidemiológicos, alegando que o que se perde nessa redução é a própria "matriz cultural", na sua acepção de fenômeno partilhado, intergeracionalmente transmitido, incorporado, produtor de teias de significado.

Pelas ciências sociais, o que se pode analisar, de modo mais profundo, são os processos pelos quais pessoas e grupos são interpelados e constituídos pelos diversos modos de se relacionar socialmente, de serem afetados por seu ambiente ecológico, de sofrerem em função de inscrições específicas no tecido social, de mediarem a sua existência no mundo a partir de atividades laborativas distintas, de ocuparem posições sociais diferenciadas e de realizarem elaborações simbólicas específicas que mediam sua relação com o mundo. Nesses processos residiriam as diferenças no modo de produzir, conceber, significar e, consequentemente, de experimentar vivências e sofrimentos psíquicos.

Tomar o social como centro das análises não significa, contudo, abdicar da reflexão de conceitos mais afeitos às psicologias, como o sujeito. Ao contrário, a teoria antropológica contemporânea reconhece que a exploração das subjetividades humanas enriquece o acesso à ordem do social. Em Sujectivity: Etnographic Investigations $^{18}$, por exemplo, subjetividade é tratada como "a atividade prática e contraditória de relacionar identidade e destino, moldados e sentidos em situações historicamente contingentes e mediadas por processos institucionais e formas culturais" e afirma-se que "subjetividade constitui o material e os meios dos sistemas de valor contemporâneo e que a acumulação de capital e governância ocorrem através do refazer da cultura como também das transformações internas na subjetividade humana". Subjetividade é tomada como categoria analítica e realidade empírica.

$\mathrm{Na}$ antropologia contemporânea são cartografadas interfaces entre as culturas e os sujeitos. Assim, os sujeitos têm acesso ao mundo através de um conjunto de práticas incorporadas (analisado, por Bourdieu ${ }^{19}$, através do conceito de corpo socialmente informado), as culturas intermediam construções de pessoa particulares, a subjetividade é forjada e modificada em interações intersubjetivas e institucionais (Goffman ${ }^{20}$ descreve magistralmente o processo de despersonalização forjado no seio de instituições totais), ou são mediadas por processos políticos (Young ${ }^{21}$, estudando a síndrome de estresse pós-traumático, configurada no pós-guerra do Vietnã, evidencia de que modo categorias psiquiátricas deslegitimam experiências humanas).

\section{As inflexões da produção do conhecimento mediadas pelo fazer etnográfico}

Uma análise etnográfica crítica tem como intenção desnaturalizar o mundo, evidenciando suas construções sociais, culturais e políticas. Nessa direção, torna-se importante discutir de que modo particularidades do fazer etnográfico modelam a construção do tipo de conhecimento (acerca) do social que lhe é próprio. Pela força da experiência de campo, a etnografia pode funcionar como um ritual de iniciação na disciplina antropológica e alimentar um exercício de reflexividade constitutivo da produção etnográfica, deslanchado a partir de um interessante movimento pendular produzido entre o estranhamento do outro e o descentramento de si, ou distanciamento daquilo que lhe é familiar ${ }^{22}$. É o modus operandi da produção de um tipo de conhecimento caracterizado também pela descoberta sensorial da alteridade e pela apreensão encarnada do caráter público (intersubjetivo) da linguagem.

A condição de possibilidade de que esse movimento se realize está na dependência de fatores ligados ao estilo pessoal do etnógrafo: abertura 
para o mundo, curiosidade, empatia, disponibilidade, vocação e treinamento. Laplantine ${ }^{22}$ chama a atenção para a ruptura com a tradição intelectualista, quando o trabalho etnográfico envolve múltiplos sentidos na compreensão dos fenômenos e requer atenção flutuante para se deixar abordar pelo inesperado. Geertz ${ }^{14}$ já falava da cultura como o lugar da educação dos sentidos, logo apreender os sentidos dos outros demanda uma atenção ao que está sendo produzido nos nossos.

Outros aspectos desse labor etnográfico estão ligados ao próprio trabalho de campo. Dentre estes, poderíamos pontuar aspectos relacionais, ligados à maior ou menor facilidade de estabelecer contato com o grupo estudado, a capacidade de tratá-los como interlocutores, e não meros informantes, criando as condições para que um encontro etnográfico - que envolva uma relação dialógica e uma fusão de horizontes aconteça ${ }^{23}$. Nessas relações, evidentemente, elementos de poder e campos de interesse se delineiam, produzindo interferências.

Outros aspectos ligados à vivência do campo podem estar em jogo, conectados especialmente ao que comumente se designa como a imersão no universo social e cosmológico do outro ${ }^{24}$. Essa imersão é alcançada pela intermediação de elementos que envolvem a relação com o espaçotempo, as vivências corporais e as experiências de linguisticidade que atravessam o viver lá. Embora, cada vez mais, etnografias possam ser realizadas em um tempo curto ${ }^{25}$, o efeito desse estreitamento temporal pode refletir-se em insights etnográficos frágeis, voláteis, fruto de elaboração insuficiente do "impacto existencial e psíquico do trabalho de campo"26, ou de fixações em momentos onde as relações com as pessoas ou com os espaços ainda são marcados por excessiva desconfiança, ou demasiado encantamento. Imersão no campo exige disponibilidade subjetiva, numa apreensão fenomenológica da mesma, que favoreça que sentidos sejam aguçados, vivências corporais experimentadas e o fascínio do extraordinário ceda progressivamente lugar aos (ou incorpore) encantos calmos do cotidiano.

Desse conjunto de modos de fazer, depreende-se o valor epistemológico atribuído a esse tipo de investigação. A etnografia, método por excelência da antropologia, passa então a ser vista como mais do que isso - como a própria teoria vivida $^{26}$ - não apenas uma prática de pesquisa, senão uma forma de renovação teórica da própria disciplina antropológica. Nesta, os dados empíricos não devem aparecer como meras ilustrações, mas como fontes de interlocução inspi- radora que atualizem a "experiência totalizadora" do ter vivido lá, reconhecendo arranjos nati$\operatorname{vos}^{27}$. No trabalho de campo reside a consecução do próprio projeto da antropologia, a saber: "formular uma ideia de humanidade construída pelas diferenças, resultado do contraste dos nossos conceitos (teóricos ou de senso comum) com outros conceitos nativos" ${ }^{\prime 2}$. Nada mais promissor para o campo da saúde mental, onde lidamos permanentemente com o desafio posto pela relação com a alteridade.

\section{Apreendendo a alteridade: aproximações entre uma clínica do sujeito e uma etnografia interpretativa}

Descentrar-se de si e apreender o outro nos seus próprios termos é uma preocupação que aproxima a antropologia de clínicas de base psicanalítica, ao modo da "clínica antimanicomial"28 e da clínica ampliada ${ }^{29}$. Ao entenderem os sintomas psíquicos de uma pessoa se conformarem enquanto um "enigma a ser decifrado ou questão a ser elaborada", e não como transtornos a serem corrigidos, elas os abordariam através de uma "minuciosa análise fenomenológica da experiência vivida pelo sujeito"28. No centro do enigma, estaria a tarefa do clínico de compreender a lógica subjacente ao sujeito, as normas de funcionamento singulares que lhe movem e que são suscitadas a partir de exigências que a sua vida e o seu contexto lhe fazem em momentos específicos. Trocando a rígida fronteira entre normal e patológico por aquela que estabelece graus de normatividade nas formas de andar a vida ${ }^{30}$, observa-se que o que está em jogo, no âmago dos conflitos psíquicos, é o potencial de normatividade de que o sujeito pode lançar mão para buscar a solução para o problema que se lhe apresenta.

O potencial normativo diz respeito ao julgamento frente a situações internas ou externas ao sujeito que mobilizam a sua capacidade criativa e geram um efeito de plasticidade diante do imprevisto. Quando este potencial se encontra diminuído, observam-se estados de enrijecimento que dão lugar às estereotipias e paralisias que configuram sintomas. O que não impede que certo potencial normativo persista na vivência enferma, evidenciado nas diversas formas das pessoas de interpretar suas experiências psicóticas ou nas múltiplas astúcias, estratégias e modos criativos de utilizar-se da cultura para mediar a sua própria forma diferente de ser nas relações que estabelecem socialmente. A análise desses jogos depende da interpretação dos comportamentos 
dos sujeitos dentro de contextos específicos (contextos psíquicos e simbólicos, mas também sociais e culturais), no que Corin e Lauzon ${ }^{17}$ propõem "interpretar os sintomas como articulações da experiência”.

Para estas convergências que apontamos entre antropologia e certas clínicas psicológicas e psicanalíticas, cabe estabelecer a importância inestimável da "guinada interpretativista" central às abordagens hermenêuticas e fenomenológicas. Nestas, conceitos como narrativas, subjetividade, corporeidade, afetos e outros, ganham proeminência. Geertz ${ }^{31}$ localiza as vertentes compreensivas em oposição às explicativas como parte de uma reconfiguração mais vasta do pensamento social, o que atinge diversas correntes do pensamento, e não apenas as vertentes interpretativas. Essa mudança é evidenciada no crescente uso de novas metáforas, dentre as principais, o drama, o teatro e o texto. Estas traduzem abordagens que trocaram "uma explicação ideal, que inclui leis e casos ilustrativos, por um tipo de explicação que envolve casos e interpretações". Elas se caracterizam por realizar "esforços para formular conceitos que expliquem como este ou aquele povo, este ou aquele período, esta ou aquela pessoa fazem sentido para si mesmos, e, quando este processo torna-se claro, buscam explicações para a ordem social, para mudanças históricas, ou para o funcionamento psíquico de um modo geral". Ou seja, há uma ênfase no acesso ao ponto de vista dos nativos, ou "naquilo que está em jogo para homens e mulheres particulares em seus mundos locais" 32 .

Nessa valorização de como o mundo é apreendido, incorporado e significado pelas pessoas e grupos culturais, depreende-se que os fenômenos ganham colorações e configurações sociais na dependência de como são vividas e dos recursos que são socialmente disponibilizados e construídos para lidar com as situações concretas. Ao mesmo tempo, as culturas não são uniformes e são menos regidas por códigos rígidos de comportamento do que por interpretações possíveis dos mesmos em condições dadas de existência e de interações sociais. Evidentemente, os horizontes interpretativos e as práticas estão sujeitos a relações de poder, a condições constrangedoras, a valores e a campos normativos, geradores do habitus, tomado aqui como disposições herdadas e adquiridas, relacionadas à posição que o agente ocupa no espaço social e que geram tomadas de posição ${ }^{33}$. Decifrar, na etnografia, as formas pelas quais os sujeitos agenciam suas práticas no espaço social aproxima-se do desvelar, na clínica, os modos pelos quais o sujeito adota uma posição frente ao que lhe sucede nas situações concretas (materiais e simbólicas).

Em seu texto seminal "Uma descrição densa: por uma teoria interpretativa da cultura”, Geertz ${ }^{14}$ identifica, na clínica, um método de investigação - indutivo, por excelência, e fortemente centrado na interpretação - guardando certa analogia com o método etnográfico: começa por um conjunto de significantes (atos simbólicos) tentando enquadrá-los de forma inteligível (análise do discurso social), o que seria diferente de começar com um conjunto de observações e tentar subordiná-las a uma lei ordenadora. Para Geertz ${ }^{14}$, “(a) tarefa essencial da construção teórica não é codificar regularidades abstratas, mas tornar possíveis descrições minuciosas; não generalizar através dos casos, mas generalizar dentro deles". São estas descrições minuciosas que buscam dar inteligibilidade a um conjunto de atos simbólicos que estariam na base da analogia com a clínica.

No entanto, e isso não é irrelevante, o que o antropólogo busca com o seu método, ainda que intermediado pelas narrativas de sujeitos, é a inteligibilidade do discurso social, enquanto que o clínico buscaria a inteligibilidade do discurso do sujeito, ainda que mediado pelas suas inscrições no social. Daí atenções portadas em diferentes ferramentas de mediação desta compreensão: para os primeiros, "categorias da língua, do pensamento e das emoções, que organizam a visão do mundo e dos seres em uma sociedade"; para os segundos, "através do método da associação livre e da escuta flutuante que desconstroem a coerência manifesta e as formas de racionalidade que organizam os discursos ordinários"34. Para além das diferenças, o desafio maior situa-se na capacidade de, a partir de cada démarche, ser capaz de pisar no solo do estranho, do bizarro, do disforme sem esmagá-lo e sem capturá-lo nas nossas formas prévias de conhecimento.

\section{Algumas chaves interpretativas da loucura indicadas nos estudos etnográficos}

Independentemente da variedade fenomenológica de experiências de sofrimento psíquico, são as psicoses, mais propícias a serem traduzidas no vocabulário êmico como loucura, aquelas que mais fortemente interpelam as pessoas, nas várias culturas, na perspectiva da busca de sua compreensão. Os estudos etnográficos e a variação dos contextos nos quais eles se inserem têm sido fontes diferenciadas na informação produzida sobre os universos das pessoas psicóticas e a es- 
pecificidade na produção de significados sobre as mesmas.

Apesar do crescimento inegável da produção etnográfica a respeito da psicose, principalmente no exterior, ela poderia ser mais estudada no Brasil. Pressupõe-se que o acesso direto a pessoas psicóticas não é encarado por muitos como uma tarefa fácil e exige vocação particular por parte do pesquisador, ou alguma experiência prévia. Essa aproximação tende a ocorrer entre pesquisadores que têm uma formação na área psi, embora ela venha atraindo mais e mais antropólogos "não iniciados no campo psi".

Entre estes, o que nos tem chamado a atenção é o caráter mais "natural" (com o perdão da palavra), ou "entre iguais" da relação produzida com os psicóticos. Isso talvez por ser esta menos mediada por recursos epistemológicos, como aqueles oferecidos pela psicopatologia ou pela psicodinâmica, que inevitavelmente funcionam como referências intertextuais (quiçá referências ostensivas) nos processos interpretativos e intersubjetivos. Lembramo-nos bem de quando, durante o trabalho de campo de um dos autores deste $\operatorname{artigo~}^{35}$, conversando com a irmã de uma mulher psicótica (tratada pelo nome de Cacilda), antes mesmo de conhecê-la, no momento no qual foi dito que Cacilda passava horas conversando, a pesquisadora perguntou, por força do ofício (de psiquiatra): "ela fala sozinha?", ao que a irmã respondeu bem naturalmente: "não, ela fala lá com as coisas dela" (referindo-se aos espíritos do Candomblé). Esse deslize foi iluminador, quando foi possível perceber que, naquele contexto de fala (o que lhe valeu para vários outros), o solilóquio não tinha valor zero, quer dizer, ele não indicava a exclusão da subjetividade.

Também ali a etnógrafa pode começar a perceber que as fronteiras entre o imaginário de Cacilda e o simbólico do Candomblé eram mais porosas do que a produção delirante aparentemente o é dos nossos sistemas simbólicos racionais. Esse contato foi uma iniciação no mundo de Cacilda, quando passou a frequentar a sua casa, ouvi-la falar com quem ela não via, continuar sem compreender um monte de coisas sobre o que ela falava, mas ser capaz de entender que os espíritos que mediavam o seu mundo, e o de outros que habitavam aquele lugar, eram importantes articuladores das suas estranhas, e por vezes atormentadas, vivências. Cacilda não deixava de ser vista como louca pela comunidade, mas esses campos semânticos, produzidos a partir do idioma religioso, ofereceriam às suas angústias maior contenção, e às suas relações com os outros, indícios de ambiguidade e brechas interpretativas capazes de mediar com maior plasticidade os conflitos que a loucura gerava.

$\mathrm{O}$ trabalho de reflexividade requerido nos iniciados nos saberes psi talvez seja de outra natureza daqueles requeridos pelos não psi, mas o que é inegável é que todo pesquisador necessita lidar com os "estranhamentos" produzidos, neste caso, pela dupla experiência - do campo sobre a loucura e da relação com as pessoas psicóticas. $\mathrm{O}$ que nos interessa discutir aqui não se resume aos aspectos subjetivos desse empreendimento, mas inclui as produções metodológicas necessárias na direção de responder às indagações próprias do campo e os insights que advêm deste trabalho.

Velpry ${ }^{36}$ parte dessa mesma expérience déroutante (desconcertante) para lançar reflexões sobre um modo diferenciado da sociologia de interpretar narrativas de pessoas psicóticas. Ela explora os desafios de um empreendimento compreensivo de pessoas com doenças mentais graves, alargando a análise ao conjunto de inscrições sociais da pessoa. Para isso, enfatiza o ponto de vista dos pacientes, a partir de suas narrativas, e busca a forma como eles organizam suas vidas e constroem uma lógica para essa organização. Segundo Velpry ${ }^{36}$, a "incerteza das realidades dos fatos", inscrita nas estranhezas das narrativas, nos seus formatos nem sempre lógicos, nas dificuldades de colocar em palavras uma situação vivida, ou nas elipses e atalhos narrativos, não pode ser reduzida à confrontação entre discurso delirante e discurso racional. A observação de outras possibilidades interpretativas, se não necessariamente produzem coerência nas narrativas, ao menos permitem complexificar os seus sentidos.

Em termos analíticos, essa incerteza sobre a realidade dos fatos evocados deve ser objeto de reflexão, sendo o estatuto do seu propósito determinado em função da interação (introduzindo a dimensão de reflexividade, de dialogicidade e, eventualmente, de transferência) na qual ele é produzido, e da sua dimensão contextual. Essa dimensão, sempre explorada em pesquisas antropológicas, permite o aprofundamento da análise das experiências e expressões psicóticas, pois, além de levarem em conta sociedades e culturas diversas, inovam no fato de as pessoas psicóticas serem examinadas fora do contexto clínico e do enquadre institucional psiquiátrico ${ }^{37}$, ou interpretando este último como apenas mais uma das inscrições sociais da pessoa. Este contato no espaço comunitário favorece outros modos de pro- 
dução de (inter)subjetividade e de relações sociais e explora estratégias afetivas, sociais, culturais e políticas de uso e de apropriação do território ${ }^{38}$.

Buscando identificar as compreensões de pessoas com esquizofrenia e as estratégias de enfrentamento que lhes permitiam viver de forma mais autônoma, Lucas ${ }^{39}$ realizou etnografia em Camberra, na Austrália, com psicóticos em situações e lugares os mais diversos da sua vida cotidiana. Ele destaca uma cultura que é ativa e estrategicamente trazida em evidência pelos seus interlocutores e que detinha a sua base material concreta nos objetos e práticas que estavam prontamente à mão no mundo cotidiano. Esses recursos expressivos eram colocados à disposição do antropólogo como uma forma de verificar e validar as experiências de alteridade. Para Lucas ${ }^{39}$, "foram as ferramentas cotidianas - linguagem, objetos, experiência biográfica compartilhada, textos populares e mídia - que pareciam efetuar melhor esse movimento [entre a compreensão e a incompreensão]. Foi o engajamento etnográfico que serviu à tarefa de construir intersubjetividade e ter feito com que experiências difíceis dos pacientes significassem alguma coisa para mim assim como para eles".

Por outro lado, esse trânsito na vida cotidiana dos outros não é capaz de produzir entendimento etnográfico se não for entremeado por um esforço interpretativo de acessar os estoques de conhecimento da cultura, suas estruturas de significação ou aquilo que está em jogo nas relações que se estabelecem entre (e com) as pessoas que estamos interagindo e estudando. Por exemplo, se não buscasse aprofundar-se nas estruturas de significado em torno de divindades e práticas rituais na sociedade indiana, Corin ${ }^{40}$ talvez não entendesse a que ponto o uso concreto de símbolos religiosos hinduístas guarda diferenças fundamentais no manejo da experiência psicótica quando comparados os psicóticos e os seus familiares. Corin ${ }^{40}$ conclui que, enquanto os pacientes, dispondo da qualidade enigmática da experiência religiosa, ou explorando sua função continente para experiências elusivas, aproximavam suas experiências àquelas do retiro dos $s a-$ dhus (místicos que renunciam aos seus bens materiais e vão viver isolados da sociedade), os familiares recorriam, em geral, aos significantes religiosos visando restaurar o cumprimento das tarefas no mundo de acordo com a noção de dharma (as leis naturais que orientam a maneira de agir e que são alcançadas pelo intermédio de rituais). Desse modo, os pacientes usavam esses símbolos de modo a tentar "nomear, domesticar e, de certo modo, integrar um penetrante sentido de estranheza; eles deixavam a estranheza intacta - e possivelmente até a protegiam"; os familiares, por sua vez, "tentavam apagar e diminuir a esquisitice do comportamento dos pacientes e integrá-los em um quadro coletivo e culturalmente texturizado" 40 .

Resultados dessa natureza afirmam o caráter instituinte próprio à diferença no modo de estar no mundo articulado a partir de linguagens e significados culturais profundos. Estes são tomados diferentemente pelos atores na dependência da questão que formulam nas suas experiências próprias mediadas pelas influências das dinâmicas sociais nas quais estão inseridos. São esses jogos - com a linguagem, com a cultura e com os outros - que interessam à etnografia de acessar a partir das histórias de vida dos sujeitos, das suas interações, das suas narrativas ou dos artefatos estéticos que possam vir a lançar mão para expressar essas experiências.

\section{Considerações finais}

Nesse percurso argumentativo, o que está em questão não é se o caminho etnográfico é capaz de produzir mais compreensão sobre as pessoas psicóticas do que um saber psicanalítico ou epidemiológico o faria. Recusamos, inclusive, compreensões definitivas ou totalizadoras, acreditando-se nos enormes desafios colocados pelo que, na psicose, encontra-se inacessível (ou indomesticável) a interpretações lógicas e racionais. O que pretendemos argumentar é que acessar pessoas psicóticas (ou outras que venham a falar das experiências psicóticas) de lugares variados no seu cotidiano e situadas a partir de suas diversas inscrições sociais e, ao mesmo tempo, confrontar essas interpretações com outras dimensões interpretativas da sua realidade social e dentro das lógicas afeitas às suas psicologias locais ${ }^{41}$, é um procedimento relevante de onde certos aspectos do entendimento sobre a loucura (ou sobre as razões da sua incompreensão) emergiriam.

Os antropólogos têm identificado essa busca de entendimento em manifestações as mais diversas nas culturas, que vão desde o contexto das instituições que se ocupam do cuidado à loucura e seus processos rituais ${ }^{42}$, passando pelas sociodinâmicas e emoções expressas que atravessam as relações entre as famílias e os seus membros psicóticos e seus efeitos sobre o prognóstico da esquizofrenia ${ }^{43}$, até chegar na articulação das experiências dos sujeitos psicóticos atra- 
vés dos idiomas culturais, permitindo formas diversas de expressão da alteridade ${ }^{35,40}$.

A apresentação do acúmulo de evidências produzidas por esses estudos mereceria um artigo específico dada a sua riqueza e a pouca sistematização nas nossas publicações. Neste texto, contudo, tentamos centrar nossas reflexões sobre as potencialidades inscritas na etnografia enquanto mediadoras de um tipo particular de conhecimento sobre saúde mental, ao nosso ver, afeito aos desafios colocados pela própria Reforma Psiquiátrica e com efeitos principalmente nos seus campos epistemológico e sociocultural.

O método etnográfico, sustentado por longos períodos de trabalho de campo e persistente engajamento nas mesmas comunidades, tem permitido uma compreensão rica e atenta das linguagens envolvidas nas expressões das experiências psicóticas, levando a sério diferentes formas de pensamento e outras formas de conhecimento próprias a essas comunidades. Essa compreensão se sustenta pela preocupação política e pela profundidade histórica, reveladas não apenas na contextualização sociopolítica e na inscrição temporal dos fenômenos estudados, mas no poder de vocalização de epistemologias e formas de agir muitas vezes marginalizadas nas sociedades onde o sistema biomédico é hegemônico. Evidenciando formas extremas de aflição, desespero e desejo através da poieses inscrita nas lutas éticas, preocupações existenciais e materialidades instantâneas das pessoas nos seus contextos de vida, a antropologia desvela alguns dos mistérios da loucura. Como dizem Bibeau e Corin ${ }^{44}$, sendo divinatória, a produção do saber antropológico é reveladora: de mistérios profundos, talvez, mas, sobretudo, daquilo que está na superfície, e não se enxerga pela excessiva banalização, pelo medo ou pelo desprezo. Essa revelação requer que nos posicionemos na intertextualidade entre as nossas referências teóricas, ou da nossa tradição cultural, e aquelas dos nossos interlocutores. Requer, quiçá, certa razão de ser não ensimesmada, política: compreender para melhor agir.

\section{Colaboradores}

MO Nunes e M Torrenté participaram igualmente de todas as etapas de elaboração do artigo. 


\section{Referências}

1. Corin E, Bibeau G, Martin JC, Laplante R. Comprendre pour soigner autrement. Montreal: Les presses de l'Université de Montréal; 1990.

2. Nunes MO. Interseções antropológicas na saúde mental: dos regimes de verdade naturalistas à espessura biopsicossociocultural do adoecimento mental. Interface (Botucatu) 2012; 16(43):973-985.

3. Almeida Filho N. Hacia una etnoepidemiología (Esbozo de un nuevo paradigma epidemiológico). Revista de la Escuela de Salud Pública 1992; 3(1):33-40.

4. Alverga AR, Dimenstein M. A loucura interrompida nas malhas da subjetividade. In: Amarante P, organizador. Archivos de saúde mental e atenção psicossocial 2. Rio de Janeiro: Nau; 2005. p. 45-66.

5. Oliveira CC, Oliveira SB, Fortunato MC, Silva AO. Loucura e Liberdade: Vivências e Convivências em Crato-CE. Rev Bras Enferm 2003; 56(2):138-142.

6. Onocko-Campos RT, Furtado JP, Passos E, Benevides R. Pesquisa Avaliativa em Saúde Mental: desenho participativo e efeitos da narratividade. São Paulo: Aderaldo \& Rothschild Editores; 2008.

7. Mielke FB, Olschowsky A, Pinho LB, Wetzel C, Kantorski LP. Avaliação qualitativa da relação de atores sociais com a loucura em um serviço substitutivo de saúde mental. Rev Bras Enferm 2012; 65(3):501-507.

8. Nunes MO, Torrenté M, Ottoni V, Moraes V, Santana M. A dinâmica do cuidado em saúde mental signos, significados e práticas de profissionais em um Centro de Assistência Psicossocial em Salvador, Bahia, Brasil. Cad Saude Publica 2008; 24(1):188-196.

9. Dias MK. A experiência social da psicose no contexto de um Centro de Atenção Psicossocial. Cien. Saude Colet 2011; 16(4):2155-2164.

10. MacRae E, Vidal SS. A Resolução 196/96 e a imposição do modelo biomédico na pesquisa social: dilemas éticos e metodológicos do antropólogo pesquisando o uso de substâncias psicoativas. Rev. Antropol. 2006; 49(2):645-666.

11. Raupp L, Adorno RCF. Circuitos de uso de crack na região central da cidade de São Paulo, Brasil. Cien Saude Colet 2011; 16(5):2613-2622.

12. Rabelo MC. Narrando a Doença Mental no Nordeste de Amaralina: relatos como realizações práticas. In: Rabelo MC, Alves PC, Souza IM, organizadores. Experiência de Doença e Narrativa. Rio de Janeiro: Ed. Fiocruz; 1999. p. 75-87.

13. Silveira ML. O Nervo Cala, O Nervo Fala: a linguagem da doença. Rio de Janeiro: Ed. Fiocruz; 2000.

14. Geertz C. Uma descrição densa: por uma teoria interpretativa da cultura. In: Geertz C. A interpretação das culturas. Rio de Janeiro: Zahar; 1978. p. 13-41.

15. Obeyesekere G. The Work of Culture. Symbolic Transformation in Psychoanalysis and Anthropology. Chicago: University of Chicago Press; 1990.

16. Durkheim E. Les règles de la méthode sociologique. Paris: PUF; 1968

17. Corin E, Lauzon G. From Symptoms to Phenomena. The articulation of experience in schizophrenia. Journal of Phenomenological Psychology 1994; 25(1):3-50.

18. Biehl J, Good B, Kleinman A. Subjectivity. Ethnographic Investigations. Berkeley, Los Angeles, London: University of California Press; 2007.
19. Bourdieu P. O conhecimento pelo corpo. In: Bourdieu P. Meditações pascalianas. Rio de Janeiro: Bertrand Brasil; 2007. p. 157-198.

20. Goffman E. Asylums. Essays on the social situation of mental patients and other inmates. New York: Anchor Books; 1961.

21. Young A. The harmony of illusion. Inventing Posttraumatic Stress Disorder. Princeton: Princeton University Press; 1995.

22. Laplantine F. A Descrição etnográfica. Paris: Armand Colin; 2005.

23. Oliveira RC. O trabalho do antropólogo. Olhar, ouvir, escrever. In: Oliveira RC. O trabalho do antropólogo. Brasília, São Paulo: Paralelo XV, Ed. UNESP: 2000. p. 17-35.

24. Peirano M. A favor da Etnografia. Rio de Janeiro: Relume-Dumará; 1995.

25. Trad LAB. Trabalho de campo, narrativa e produção de conhecimento na pesquisa etnográfica contemporânea: subsídios ao campo da saúde. CIen Saude Colet 2012; 17(3):627-633.

26. Peirano M. Etnografia, ou a teoria vivida. Pontourbe 2008; 2(2).

27. Magnani JG. De perto e de dentro: notas para uma etnografia urbana. Revista Brasileira de Ciências Sociais 2002; 17(49):11-29.

28. Bezerra Júnior B. Um apelo à clínica: nem o respaldo da norma, nem o extravio da dor. In: Caderno Saúde Mental. A Reforma Psiquiátrica que queremos: por uma clínica antimanicomial. Belo Horizonte: ESP; 2006

29. Tenório F. A psicanálise e a clínica da reforma psiquiátrica. Rio de Janeiro: Rios Ambiciosos; 2001.

30. Canguilhem G. Le normal et le pathologique. Paris: Presses Universitaires de France; 1943.

31. Geertz C. Mistura de gêneros: a reconfiguração do pensamento social. In: Geertz C. O Saber Local: Novos Ensaios em Antropologia Interpretativa. Petrópolis: Vozes; 2003. p. 33-56.

32. Kleinman A. Suffering and its Professional Transformation. Toward an Ethnography of Interpersonal Experience. In: Kleinman A. Writing at the Margin. Discourse between Anthropology and Medicine. Berkeley, London: University of California press; 1995. p. 95-119.

33. Bourdieu P. Le sens pratique. Paris: Minuit (Le Sens Commun); 1980.

34. Corin E. Le heurt des langues. Psychanalyse et anthropologie em dialogue. Anthropologie et Sociétés 2010; 34(3):9-22.

35. Nunes MO. À temps et à contre-temps: les voix des tambours dans l'expérience des psychotiques [tese]. Montreal: Université de Montréal; 1999.

36. Velpry L. Le quotidien de la psychiatrie. Sociologie de la maladie mentale. Paris: Armand Colin; 2008.

37. Estroff S. Making it Crazy. An Ethnography of Psychiatric Clients in an American Community. Berkeley, London: University of California Press; 1981.

38. Santos MRP, Nunes MO. Território e saúde mental: um estudo sobre a experiência de usuários de um Centro de Atenção Psicossocial, Salvador, Bahia, Brasil. Interface (Botucatu) 2011; 15(38):715-726. 
39. Lucas R. In and out of culture: Ethnographic means to interpreting Schizophrenia. In: Jenkins JH, Barret RJ, organizadores. Schizophrenia, Culture and Subjectivity. The Edge of Experience. Cambridge: Cambridge University Press; 2004. p. 146-163.

40. Corin E. The Other of Culture in Psychosis. The ExCentricity of the Subject. In: Biehl J, Good B, Kleinman A, editors. Subjectivity. Ethnographic Investigations. Berkeley, London: University of California Press; 2007. p. 273-314.

41. Good B. The Subject of Mental Illness. Psychosis, Mad Violence, and Subjectivity in Indonesia. In: Biehl J, Good B, Kleinman A. Subjectivity. Ethnographic Investigations. Berkeley, London: University of California Press; 2007. p. 243-272.

42. Devisch R. Soigner l'affect em remodelant le corps en milieu Yaka. Anthropologie et Sociétés 1993; 17(1-2):215238.

43. Jenkins JH. Anthropology, Expressed Emotion, and Schizophrenia. Ethos 1991; 19(4):387-431.

44. Bibeau G, Corin EE. From Submission to the Text to Interpretive Violence. In: Bibeau G, Corin EE, editors. Beyond textuality. Ascetism and Violence in Anthropological Interpretation. Berlin, New York: Mouton de Gruyter; 1995. p. 3-54.

Artigo apresentado em 29/03/2013

Aprovado em 11/04/2013

Versão final apresentada em 16/04/2013 